\title{
A review of using green chemistry methods for biomaterials in tissue engineering
}

This article was published in the following Dove Press journal:

International Journal of Nanomedicine

\author{
Hossein Jahangirian' \\ Ensieh Ghasemian \\ Lemraski $^{2}$ \\ Roshanak Rafiee- \\ Moghaddam' \\ Thomas J Webster' \\ 'Department of Chemical Engineering, \\ Northeastern University, Boston, \\ MA, USA; ${ }^{2}$ Department of Chemistry, \\ Faculty of Science, llam University, \\ Ilam, Iran
}

\begin{abstract}
Although environmentally safe, or green, technologies have revolutionized other fields (such as consumables, automobiles, etc.), its use in biomaterials is still at its infancy. However, in the few cases in which safe manufacturing technology and materials have been implemented to prevent postpollution and reduce the consumption of synthesized scaffold (such as bone, cartilage, blood cell, nerve, skin, and muscle) has had a significant impact on different applications of tissue engineering. In the present research, we report the use of biological materials as templates for preparing different kinds of tissues and the application of safe green methods in tissue engineering technology. These include green methods for bone and tissue engineering-based biomaterials, which have received the greatest amount of citations in recent years. Thoughts on what is needed for this field to grow are also critically included. In this paper, the impending applications of safe, ecofriendly materials and green methods in tissue engineering have been detailed.
\end{abstract}

Keywords: ecofriendly, safe material, scaffold, green chemistry, biomaterials, tissue engineering, nanomedicine, nanoparticle

\section{Introduction}

Tissue engineering combines the principles of biologically active molecules, scaffolds, engineering, and material fabrication to construct, reform, or treat damaged tissues or organs. Green chemistry is the use of safe and clean materials and methods to reduce the toxic and harmful results of scientific research. Hence it uses safe energy or decreases the waste materials by different experimental and industrial synthetic methods. The important goal of green methods and technology is to decrease the adverse effects of pollution on the environment or human body. Apart from the positive effects of ecofriendly life, there are many drawbacks in green chemistry, such as high cost, lack of scientific information about used chemical, raw materials, technology, and the result of the constant use of natural materials. ${ }^{1}$

In this study, we report the application of more safe and green methods and materials used in tissue engineering technology. ${ }^{2,3}$

Based on reported data, important techniques have been used in the reported research for the preparation of real scaffolds instead using real organ are bioprinting, rapid prototyping technologies, polymer solution casting, gas foaming, emulsification freeze-drying, thermally induced phase separation, electrospinning, computer-aided design and computer-aided manufacturing technologies, laser-assisted bioprinting, and assembly methods. ${ }^{4-10}$ Application of these techniques is along with advantages and drawbacks.

The major challenges of these methods are to propagate safe industrial and medical products. One of the most important strategies to decrease pollution and toxic materials
Correspondence: Hossein Jahangirian Department of Chemical Engineering, 313 Snell Engineering Center, Northeastern University, 360 Huntington Avenue, Boston, MA 02II5, USA

Email kamran.jahangirian@gmail.com
International Journal of Nanomedicine 2018:13 5953-5969

5953

(c) (1) (\$) $\odot 2018$ Jahangirian et al. This work is published and licensed by Dove Medical Press Limited. The full terms of this license are available at https://www.dovepress.com/terms.php

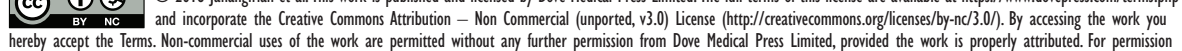
for commercial use of this workl, please see paragraphs 4.2 and 5 of our Terms (hitpps//www.doveperess.com/terms.php). 
is the application of agricultural or animal wastes as an initial material for different research and experiments.

Furthermore, biomaterials have generated great interest to decrease the adverse effects of other methods, as they can be produced in large amount with same physical, chemical, and structural properties for a wide range of tissue types. Polymer-based biomaterials such as polysaccharides and proteins with different applications in tissue regeneration have been prepared from both natural and synthetic materials. As an example, chitosan (CS), an acceptable biocompatible and biodegradable polysaccharides with different chemical functions, is a promising material for progressing in tissue engineering during cellular functioning and differentiation. In addition, collagen and hyaluronic acid (HA), protein-based biomaterials, have been extracted from natural resources and used in different restoration or improvement scaffolds. ${ }^{11}$

Biocompatibility of natural materials is dependent on the acceptance of the body organs, without any harmful effects later than replacement. ${ }^{10}$

\section{Bone tissue engineering}

For many years, treatment or replacement of damaged bone scaffold due to trauma, injury, and disease has been one of the most important human concerns in medical science. In addition, increasing and changing the level of expectations of humans is another reason why tissue engineering has a special place in applied sciences. Current methods and technology to maintain or restore important parts of damaged bone tissue come with notable limitations and intrinsic disadvantages that may be harmful; herein, we focus on the present research that uses safe, and green, materials as an alternative. ${ }^{12}$

\section{Hydroxyapatite or hydroxylapatite (HAP) based on bone tissue}

HAP is a natural resource of calcium apatite with chemical structure $\mathrm{Ca}_{10}\left(\mathrm{PO}_{4}\right)_{6}(\mathrm{OH})_{2}$ and hexagonal crystal structure. Pure HAP powder is white in color. More than $50 \%$ by volume and $70 \%$ by weight of human bone are composed of modified HAP or bone mineral. Carbonated calcium-deficient HAP is an important material in dental composition. ${ }^{13}$

HAP has a proper potential to become a bone replacement material, as it has the same structure of natural bone. The application of modified HAP as a green, renewable biomaterial opens up hopeful situation for the synthesis of bone-based implants and different drugs for the treatment of bone lesions. During the green synthesis of materials, synthetic methods should be arranged for preparing compounds that contain little or no toxicity to human health and the environment. ${ }^{14-16}$
For example, Zhou et $\mathrm{al}^{17}$ introduced modifications in HAP to decrease the need for hazardous chemicals in tissue engineering by preparing type I collagen in an ecofriendly PBS/ethanol solvent instead of the ordinary toxic organic compounds. Structural analysis confirms a monotonous and porous structure of the synthesized collagen/HAP nanofiber generated by the desalination and coelectrospinning method. ${ }^{17}$

D'Agostino et $\mathrm{al}^{18}$ used porous HAP granules mixed with microfibrillar collagen as cheekbone augmentation in 430 patients and the expectation of the patients has been fulfilled.

Application of nano-HAP (nHAP) in orthopedics due to its similarity in size, crystallography, and structure with bone scaffold is noticeable. As an example, the high biological interest in nHAP composites with different fatty acids such as linoleic acid, lauric acid, and oleic acid have been recently reported. In vitro assay confirmed more acceptances in biocompatibility and cell proliferation of synthesized nHAP when compared with conventionally made HAP. These results indicated that fatty acids would be a harmless and safe candidate for bone tissue engineering applications. ${ }^{19}$

A safe and economic method for the preparation of nanostructure HAP using recycled eggshell biowaste is another example based on green chemistry. This mechanism includes the combination of eggshell biowaste as a resource of calcium and ammonium dihydrogen orthophosphate as a phosphate resource. Ultrasound-mediated chemical preparation of HAP is also an established application, a same method wherein commercially available calcium hydroxide and ammonium dihydrogen orthophosphate were applied as calcium and phosphate sources, respectively. ${ }^{20}$

Sometimes combination of two or more components increases the quality and applicability of materials; for example, bamboo fiber/nHAP/poly(lactic-co-glycolic acid) (PLGA) composite has been made by a freeze-drying method. The effect of structural and environmental parameters such as different freezing temperatures, concentrations, and pore-forming agents on the surface morphology and physical properties of the tissue were determined by scanning electron microscopy, a modified liquid displacement method, and an electromechanical universal testing machine, respectively. The data analysis showed that the bamboo fiber/nHAP/PLGA composite scaffolds had the expected porosity when compared with nHAP/PLGA composite scaffolds. Furthermore, the in vitro experiments in the similar body system showed that the application of bamboo fiber in the scaffolds accelerated the bamboo fiber/ 
nHAP/PLGA degradation and showed high cytocompatibility. Due to the improving properties of nHAP/PLGA as a material in tissue engineering, the bamboo fiber/nHAP/ PLGA would be a hopeful candidate for bone scaffold regeneration. ${ }^{21}$

One of the mineralized and natural hybrid materials usually used in bone tissue engineering with suitable mechanical strength is calcium phosphate-mineralized organic-inorganic hybrid composed of nHAP, CS, chondroitin sulfate (CSA) and HA, natural polysaccharides with hierarchical micro/ nanostructures. These nHAP composites are reported as bioceramics in the literature and have different applications for their biocompatibility, bioactivity, conductivity, and safe and anti-inflammatory nature. ${ }^{22}$ Figure 1 shows the synthesis mechanism of this hybrid scaffold with freeze-drying technology. The homogeneous pore size and well mechanical strength of the composites are due to the use of the nHAP and the interaction between the positive and negative points of CS and HA. Similarly, biocompatibility was evaluated by MTT cytotoxicity assays, alkaline phosphatase (ALP) activities, and Hoechst fluorescence staining, which confirmed that the expected biocompatibility, low cytotoxicity, and the components increased the proliferation and differentiation of osteoblasts. Generally, nHAP/CS/CAS/HA composite would be a good potential for the treatment or regeneration of bone scaffolds. ${ }^{22}$
Due to a lack of systematic evaluation of HAP and $\beta$-tricalcium phosphate (TCP) composite scaffolds for bone repair, their distinctions on bone regeneration have not been clarified yet. Xu et al used HAP and $\beta$-TCP to prepare composite scaffolds for bone repair. In that study, HAP and TCP with PLGA composites were prepared and their performance toward the repair of rabbit calvarial bone defects was systematically investigated. The HAP/PLGA scaffold exhibited improved mechanical strength and cell proliferation in vitro and, thus, achieved better bone repair at an earlier period than the TCP/PLGA scaffold. In contrast, the TCP/PLGA scaffold displayed greater potential in long-term bone defect repair, as TCP possessed higher alkalinity and in vivo absorbability, which was strongly evidenced by micro-computed tomography reconstructions and histological examinations. Taken together, the TCP/PLGA scaffold is thought to be the better scaffold for bone treatment or regeneration, and when morphology of the scaffolds was controlled, TCP was regarded as a superior bioceramic for structured tissue-engineering scaffolds for bone repair. ${ }^{23}$

$\mathrm{CS}$, HAP, and magnetite $\left(\mathrm{Fe}_{3} \mathrm{O}_{4}\right)$ have been broadly used for bone treatment applications. Application of composite biomaterials improves the special properties of each compound and completely distinguishes the composite effects. The structural analysis of pure CS, CS/HA, CS/ $\mathrm{HA} / \mathrm{Fe}_{3} \mathrm{O}_{4}$, and $\mathrm{CS} / \mathrm{Fe}_{3} \mathrm{O}_{4}$ was determined by measuring
A

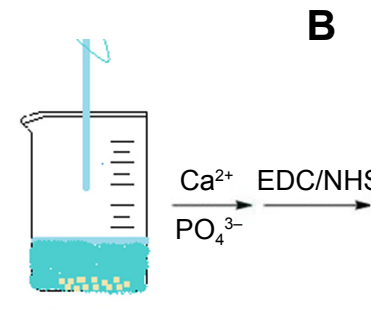

CS, CSA, HA
B

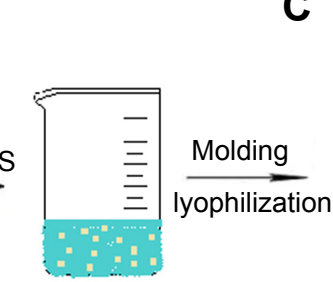

Precursor mixture

C

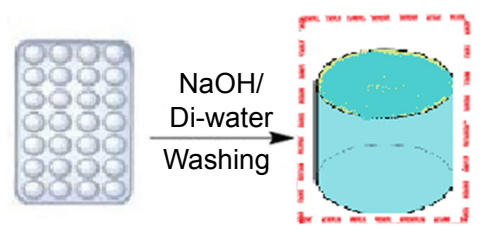

Intermediary scaffolds nHAP/CS/CSA/HA hybrid scaffolds

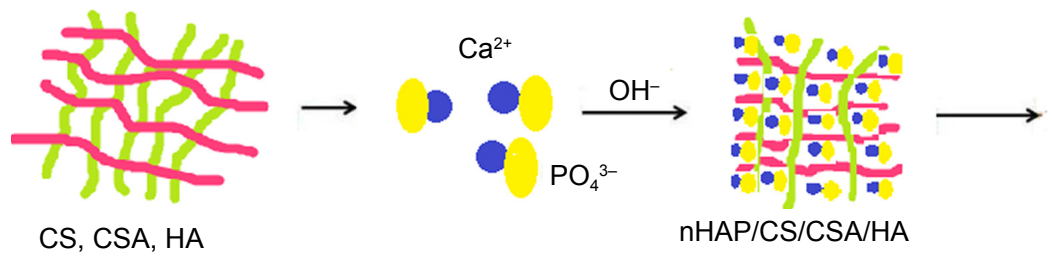

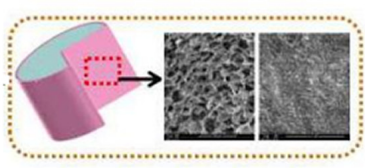

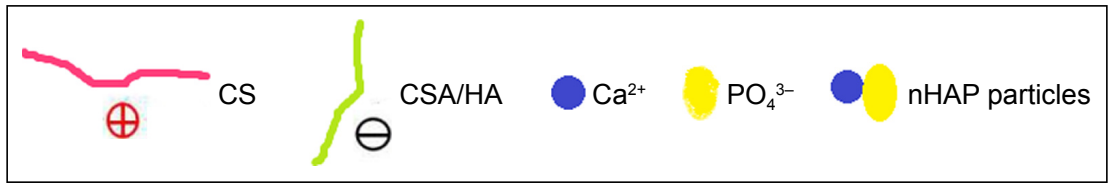

Figure I (A-C) Preparation mechanism of green hybrid nHAP/CS/CSA/HA scaffolds. Data from $\mathrm{Hu} \mathrm{Y}$ et al. ${ }^{22}$

Abbreviations: CS, chitosan; CSA, chondroitin sulfate; EDC, I-Ethyl-3-(3-dimethylaminopropyl)-carbodiimide; HA, hyaluronic acid; nHAP, nanohydroxyapatite; NHS, $\mathrm{N}$-hydroxysuccinimide. 


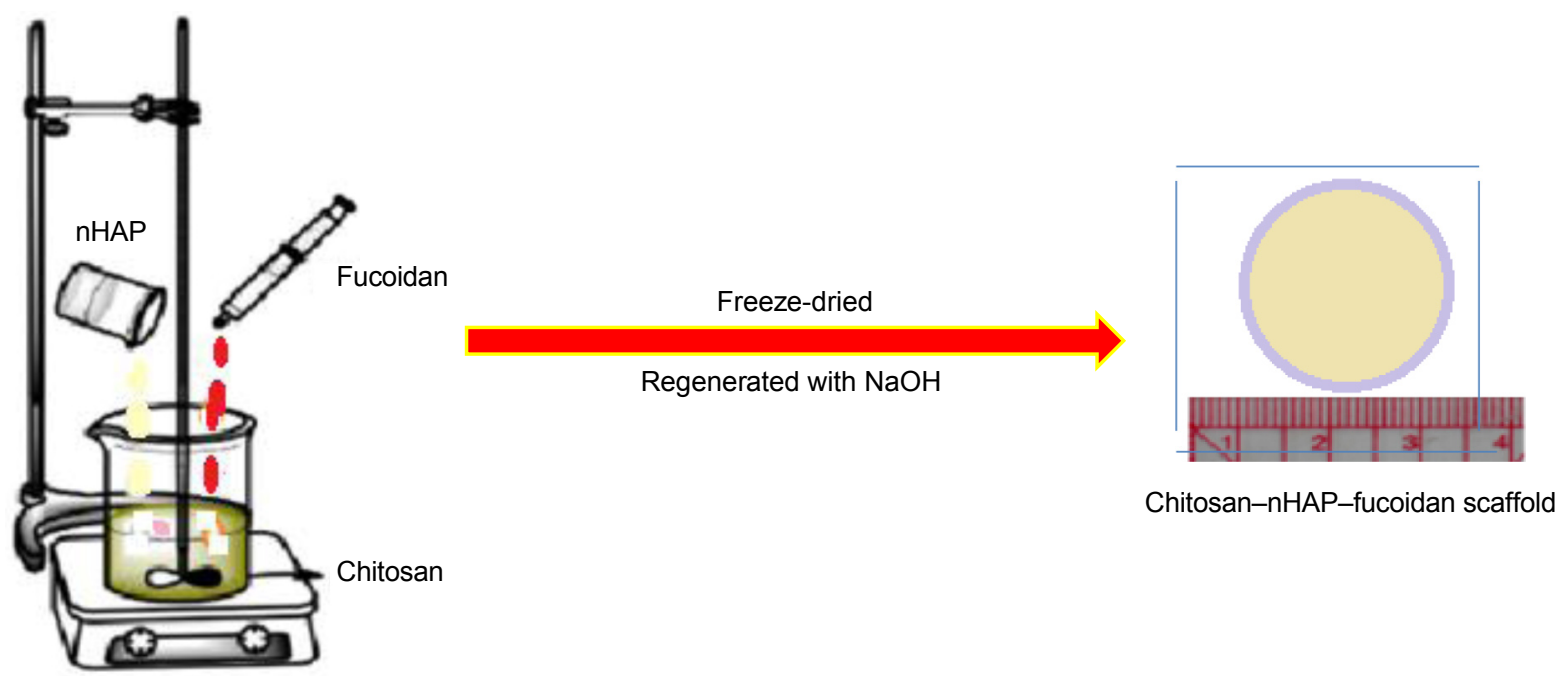

Figure 2 Synthesis of scaffolds based on chitosan, nHAP, and fucoidan. Data from Lowe B et al. ${ }^{26}$ Abbreviation: nHAP, nanohydroxyapatite.

bending strength, elastic modulus, compressive strength, and hardness values. In addition, the biological responses of human mesenchymal stem cells (hMSCs) on different composites showed acceptable in vitro biocompatibility and enhanced mechanical properties in comparison with pure CS. ${ }^{24}$

CS-based risedronate/zinc-HAP intrapocket dental film (CRZHDF) used for improving alveolar bone loss is another example of the application of modified HAP in bone tissue engineering. ${ }^{25}$

The preparation of multifunctional bioinspired tissues with vascularization and its treatment applications is noticeable for using in bone scaffolds. The solid three-dimensional (3D) tissues were prepared from CS, nHAP, and fucoidan as natural materials using the freeze-drying method (Figure 2). The application of nHAP in the CS-fucoidan composite decreased the water uptake and water retention. In vitro test including periosteum-derived mesenchymal stem cells (PMSCs) confirmed microstructure of composite, which is one of the most important properties for cell growth and nutrient supplementation. The cells showed advanced biocompatibility and excellent mineralization for the composed scaffold as a great potential in the treatment and restoration of the injured bone tissues. ${ }^{26}$

Some examples of the synthesis of HAP-based tissues based on green chemistry are given in Table 1.

\section{Polymers and biopolymers}

Various biopolymers have been used as safe source in bone tissue engineering. More research showed that the existence of green and safe materials in nature with a similar chemical structure of natural bone is a positive point in bone tissue engineering compared with the other fields in medical science and products. ${ }^{27}$

Poly (ester amide) is one of the biodegradable biopolymers that has recently been noticed as a safe material for favorable mechanical strength and structural and physical properties. As an example, poly(ester amide)-graft-tetraaniline copolymers (PEA-g-TA) showed great conductivity, mechanical strength, and biodegradability. In vitro study of the PEA$g$-TA copolymers indicated nontoxicity, sufficient adhesion, and propagation of mouse preosteoblastic MC3T3-E1 cells. Furthermore, the PEA-g-TA copolymers stimulated by a pulsed electrical signal could allow the differentiation of MC3T3-E1 cells when compared with tissue culture-treated polystyrene. The biodegradable and conductive PEA-g-TA copolymers is advantageous in using them as a source for bone tissue regeneration in vivo. ${ }^{27}$ Another insoluble polymer solution, including calcium and phosphorous precursors, was prepared by Moeini et al. The study revealed that the

Table I Application of green chemistry principles in HAP-based bone tissues

\begin{tabular}{|c|c|c|}
\hline Tissue & Green chemistry principle & Reference \\
\hline Collagen/HAP & Safer solvents and auxiliaries & 18 \\
\hline $\begin{array}{l}\text { Bamboo fiber/nano-HAP/ } \\
\text { poly(lactic-co-glycolic) }\end{array}$ & Use of renewable feedstocks & 21 \\
\hline $\begin{array}{l}\text { Nano-HAP/CSA and } \\
\text { hyaluronic acid }\end{array}$ & Designing safer chemicals & 22 \\
\hline $\begin{array}{l}\text { HAP/ } \beta \text {-tricalcium } \\
\text { phosphate }\end{array}$ & Atom economy & 23 \\
\hline CS, HAP, and magnetite & Use of renewable feedstocks & 24 \\
\hline
\end{tabular}

Abbreviations: CS, chitosan; CSA, chondroitin sulfate; HAP, hydroxyapatite. 


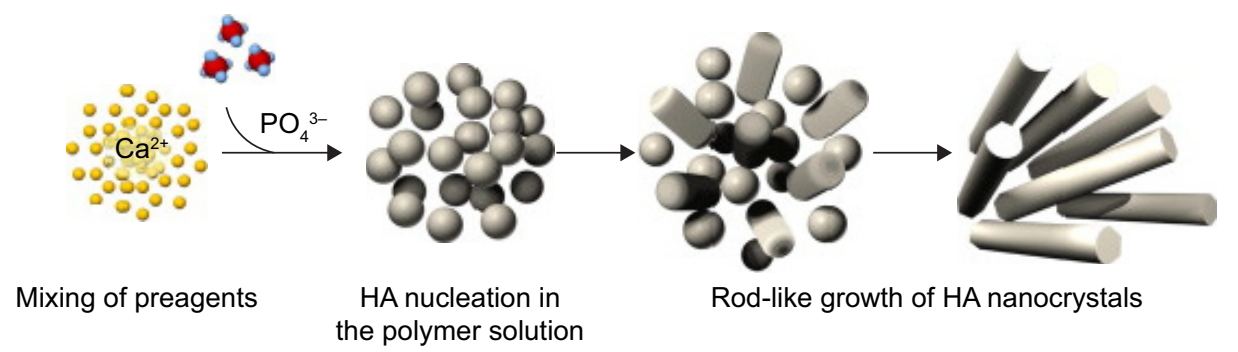

Figure 3 Mechanism of the nucleation and growth of HAP components. Data from Moeini $\mathrm{S}$ et al. ${ }^{28}$ Abbreviation: HAP, hydroxyapatite.

elastic modulus and mechanical strength of the prepared compound were higher in the in-situ method than the ex-situ one (ie, blended HAP nanorods with the polymer solution) (Figure 3). The increased bone treatment potential of the nanocomposites was showed via an in vitro bioactivity test in a similar body fluid. Enhanced cell viability and proliferation was also established by using the MTT assay in human osteosarcoma cell lines. The reported tissue with in vitro regeneration promising could be helpful for orthopedic uses and maxillofacial surgery. ${ }^{28}$

The efficiency of prepared bone tissues could be tested by cell attachment, infiltration, morphogenesis, proliferation, and differentiation, which are indicated or hardly affected by the chemical component, construction, physical, and biomedical properties of scaffolds.

Recently, a novel tissue with a special shape, good surface morphology, and adjustable biological characters based on recombinant human bone morphogenetic protein-2 (rhBMP-2)-loaded calcium phosphate (Ca-P) nanoparticle/ poly(L-lactic acid) (PLLA) nanocomposite has been prepared by cryogenic $3 \mathrm{D}$ printing method. ${ }^{29}$ The mechanical property is similar to human cancellous bone. The Ca-P nanoparticlecombined tissue layer and rhBMP-2-encapsulated scaffold layer were prepared in different kinds of emulsion solution as printing inks. Other positive points of this tissue are the sustained release of $\mathrm{Ca}^{2+}$ ions and rhBMP-2, favorable hierarchical porosity, double transformation of $\mathrm{Ca}^{2+}$ ions and rhBMP-2, sufficient cell viability, and osteogenic differentiation, which has suggested its promising in bone regeneration. ${ }^{29}$

Synthetic methods for tissue regeneration must be accompanied using and generating scaffolds that contain a little toxic effect in human body cells and life. As an example, concentric ring-aligned polycaprolactone/poly(D,L-lactideco-glycolide) (PLGA)/collagen type I-based annulus fibrous showed high water adsorption capacity to prepare hydrated native intervertebral disks. Long-term in vivo implantation tests showed an enhanced functional properties. ${ }^{30}$
Various biopolymers and peptides have been used as body's native extracellular matrix (ECM), such as pectin and polysaccharide-based components. ${ }^{31}$ Pectin with similar chemical composition to alginate extracted from the plant cell walls has been used as a great potential for artificial ECM. Modified pectin with an Arg-Gly-Asp (RGD) including oligopeptide has been applied as an ECM, which is an alternative to immobilize cells for bone scaffold preparation. The study of viability, metabolic activity, structure, and osteogenic differentiation of composites suggests the applicability of this composite to maintain immobilized cells viability and differentiating. The incorporation of the RGD peptide on a pectin backbone increased cell adhesion and proliferation within the microspheres. In contrast, growing cells in 3D structures produce a mineralized ECM. These characters proposed that pectin would be an insertable cell vehicle for green bone scaffold preparation. ${ }^{32}$

PLGA, modified by using nanodiamond phospholipid compound by physical mixing method, is a safe potential for bone tissue engineering. Modification of nanodiamond by phospholipids changed hydrophilic surface to amphipathic. In comparison with the pure PLGA, the use of nanodiamond phospholipid compound improved physical and surface parameters, such as reduction in the water contact angle and increase in hardness. Also, as a new matrix for human osteoblast growth, different amounts of a composite did not show any harmful effects on cell proliferation and osteogenic differentiation. In addition, the result of a nanodiamond phospholipid composite used for mice during 8 weeks demonstrated an good immune results and decreased biodegradation rate of a PLGA composition. ${ }^{33}$ Figure 4 shows the mechanism of preparation of PLGA, modified with a nanodiamond phospholipid compound during a green method. ${ }^{33}$

The biodegradation and structural characters of the 3D porous tissue composed of PLGA/nanofluorohydroxyapatite microspheres by a sintering method as potential bone tissue engineering were also studied. ${ }^{34}$ The biodegradation of both PLGA/nanofluorohydroxyapatite and PLGA tissues 


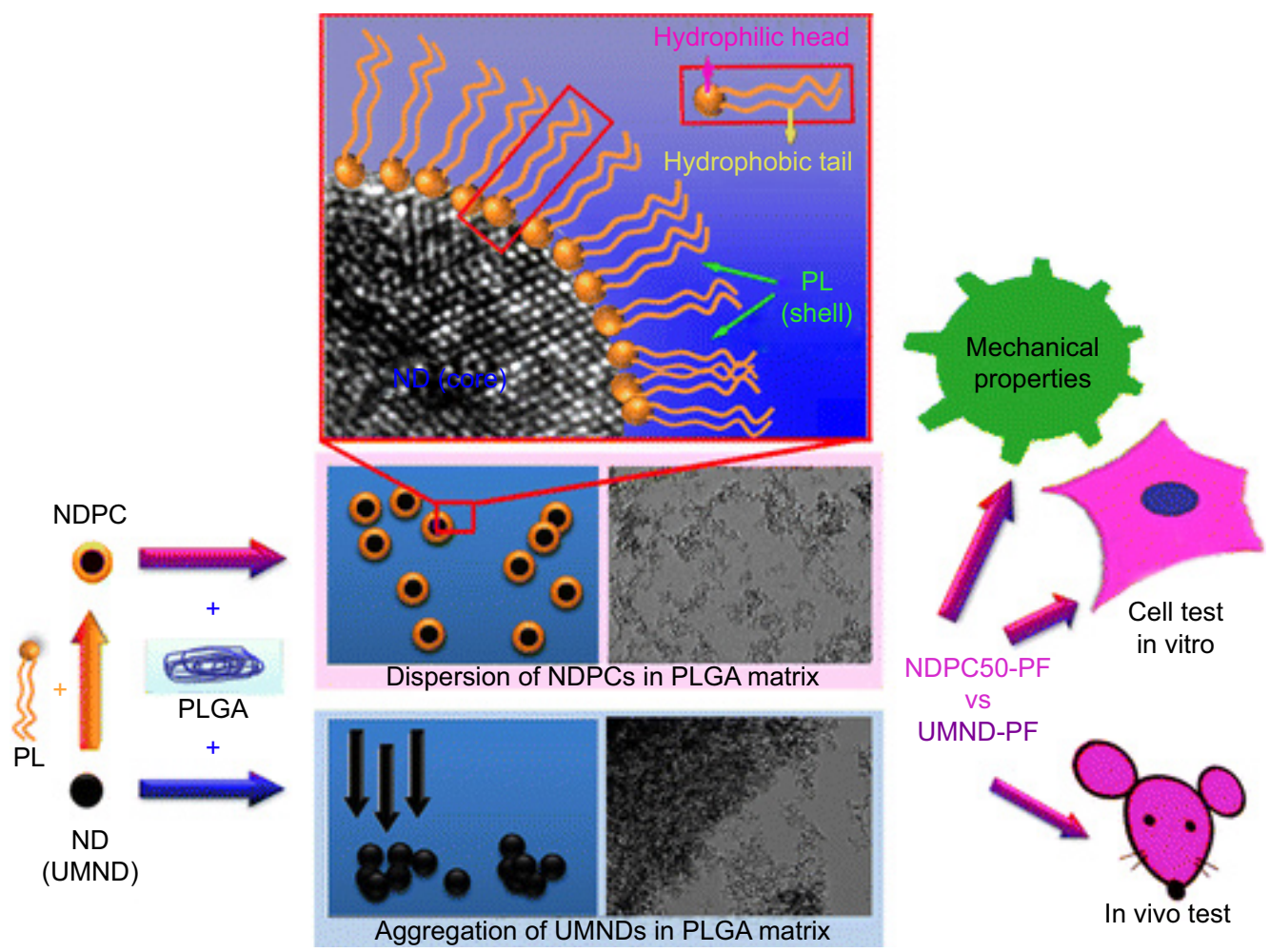

Figure 4 Mechanism of the preparation of PLGA loaded with a nanodiamond phospholipid compound. Data from Zhang $\mathrm{F}$ et al. ${ }^{33}$

Abbreviations: NDs, nanodiamond; NDPC, ND-phospholipid compounds; PF, pure PLGA film; PL, phospholipids; PLGA, poly(lactic-co-glycolic acid); UMND-PFI0, PLGA film with unmodified ND.

indicated a monotonous trend vs degradation time, due to the insertion of nanofluorohydroxyapatite in a polymeric composite. The results confirmed enhanced mechanical properties of the nanocomposite than that of the PLGA scaffold after incubation in simulated body fluid. Furthermore, the MTT test and ALP activity results showed an increase in cell viability vs time in comparison with the control group. Overall, the obtained data showed that PLGA/ nanofluorohydroxyapatite scaffolds are the great candidates for green bone regeneration. ${ }^{34}$ Some examples of biopolymers for bone regenerating based on green chemistry are given in Table 2.

Table 2 Green biopolymers for bone tissue engineering

\begin{tabular}{lll}
\hline Bone tissue & $\begin{array}{l}\text { Green chemistry } \\
\text { principle }\end{array}$ & Reference \\
\hline Hydroxylapatite nanorods & $\begin{array}{l}\text { Less hazardous chemical } \\
\text { syntheses }\end{array}$ & 28 \\
Safer solvents and & 29 \\
auxiliaries & Designing healthy & 30 \\
bone & $\begin{array}{l}\text { compounds } \\
\text { Alginate hydrogel-based } \\
\text { nucleus pulposus }\end{array}$ & 32 \\
$\begin{array}{l}\text { Modified pectin } \\
\text { Poly(lactic-co-glycolic acid)/ } \\
\text { nanofluorohydroxyapatite }\end{array}$ & Atom economy & 34 \\
\hline
\end{tabular}

Abbreviation: $\mathrm{CaP}$, calcium phosphate.

\section{Silk-based bone tissue engineering}

Based on excellent biological strength and mechanical strength, such as biocompatibility and biodegradability, silk fibroin has been intensively explored for tissue engineering and improving injured body organs as a natural, green, and safe material. ${ }^{35}$

The modification of 3D porous structure of silk fibroin using graphene oxide (GO) by freeze-drying method and using nontoxic solvent same as glycerol has been recently reported. Performing the preparation and modification of reactant in glycerol and without any toxic organic solvents confirmed "green" chemistry. By using GO, the average size of pores of the tissue decreased and improved the compressive silk II structure significantly. The results of biological activity of the silk fibroin/GO tissues involved degradability, drug release, and biocompatible properties. In comparison with the silk fibroin, tissues showed that the modification with GO increased the applicability of the tissues to resist enzyme degradation. The results of release test on Simvastatin as a model drug showed that Simvastatin release was dependent on the GO amount in tissue composition. In addition, the application of Simvastatin was sufficient to the growth of osteoblasts and the silk fibroin/GO/Simvastatin scaffolds showed higher cytocompatibility. These novel 3D 
simvastatin/GO composites with great drug release potential suggest a promising scaffold for bone tissue regeneration. ${ }^{35}$

Nanocomposite scaffolds made of natural silk fibroin and titanium dioxide $\left(\mathrm{TiO}_{2}\right)$ nanoparticles are another biofunctional agent for the restoration or treatment of the bone tissues. Structural, bioactivity, and biocompatibility characters of the prepared tissue were indicated by immersion in simulated body fluid. Results demonstrated that the porosity in the prepared scaffolds decreased with the application of higher content of $\mathrm{TiO}_{2}$ nanoparticles, resulting in an enhancement in mechanical strength. Macroporous structures with open interconnected and directional pores were successfully prepared without using any progeny or toxic solvent. ${ }^{30}$ The osteoblast-like cells indicated a high loading and proliferation on these tissues, and their viability depended hardly on the amount of silk fibroin. ${ }^{36}$

\section{Skin tissue engineering}

Currently, there are only a few dermo-epidermal substitutes that require patients with an injured dermis to receive both epidermis and dermis substitutes. Skin grafting remains the most popular treatment for skin replacements. Behind these positive points, expensive method, sub-normal skin structure, and inconsistent engraftment, spectacularly in heavy burns, are the most important limitations of these compounds.

\section{Glucose-based skin tissue engineering}

Biomaterials including polysaccharides have been used as green source for the regeneration of skin tissues. Recently, an impressive nanofibrous of Beta vulgaris (obtained from the beet [Chenopodiaceae or Amaranthaceae]) was prepared via electrospinning. Scanning electron microscopy confirmed the monotonous surface of nanocomposite of nylon polymer and B. vulgaris extracts. Mechanical strength and immunocytochemistry of the composites are comparable to the native skin tissues. These results proposed that the original functions of keratinocytes were hardly maintained using the green composite scaffolds. ${ }^{37}$

Zulkifli et al prepared hydroxyethyl cellulose (HEC)/ silver nanoparticles (AgNPs), via a safe and nontoxic method, as a great candidate for skin regeneration or improvement. The aqueous solution of substrates with different amounts of $\mathrm{AgNO}_{3}$ was prepared in HEC. The results showed noticeable morphology, good degradability, and high water absorption capacity in all the composites. The results showed not any toxicity of HEC/AgNPs composite, and so this composite could be used as a promising compound in skin tissue regenerating. Silver ions were reduced by using HEC as a reducing matter in a safe and ecofriendly solution and without any template. This is a safe and easy method for preparing AgNPs through in situ mechanism. ${ }^{38}$

Bacterial cellulose is another great candidate with efficient ability in biomedical applications such as biodegradability, network structure, high mechanical strength, good water absorption capacity, easy preparation, structure like to plant cellulose, and ability for modifying. However, it still lacks some desirable properties especially for the application in tissue engineering, due to insufficient porosity structure and low biodegradability in the body organs, which limits its application in medicine. ${ }^{39}$ Therefore, sometimes, the properties of bacterial cellulose need to be modified to a sufficient level.

For example, a novel bionanocomposite was prepared by inserting keratin (extracted from the human hair) to the bacterial cellulose (prepared by Acetobacter xylinum) to increase dermal fibroblast attachment. ${ }^{39}$ The bacterial cellulose-based nanocomposite has been prepared via two methods: in situ and postmodification. In vitro experiments with human skin keratinocytes and human skin fibroblasts confirmed the capability of the new bacterial cellulose/keratin nanocompound for the application in skin tissue engineering. Cell culture tests indicated a great modification in the surface of the bacterial cellulose/keratin nanocomposites for attaching or maintaining the material. ${ }^{39}$ Synthesis of keratin/bacterial cellulose nanocomposite mechanism and application for skin tissue engineering are given in Figure 5.

\section{Protein-based skin tissue engineering}

Polymer blending is a safe method usually applied to prepare composites with superior character better than the native material in tissue engineering. ${ }^{40}$ Recently, a novel scaffold was prepared by electrospinning method and applying a polyester (polycaprolactone), polysaccharide (CS), and protein (gelatin extracted from cold water fish skin) by Gomes et al. The properties such as surface porosity, water contact angle, mechanical strength, chemical structure, and degradability in water and cell culture medium scaffolds were characterized. Results demonstrated the hydrophilic nanofibrous tissue due to the good morphology of prepared fiber mats. Results of cell populations confirmed an enhanced large phase in comparison with the real samples; however, cell proliferation occurred on all tissues until confluence was reached. ${ }^{40}$

Inserting the biological compounds such as glycosaminoglycans (GAGs) in scaffolds is another safe and green approach toward progressing a new production of great biomaterials. Recently, gelatin and various amounts of 


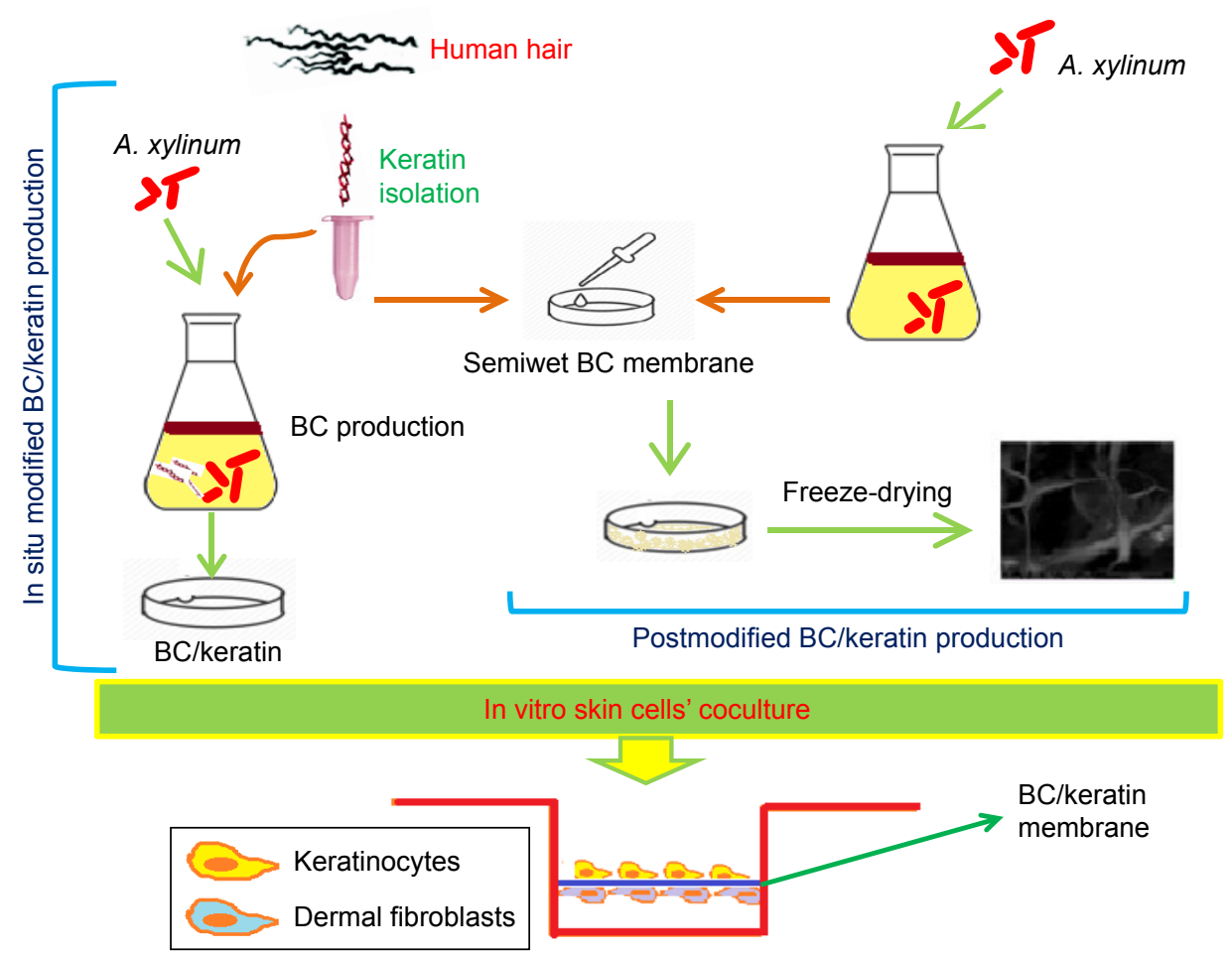

Figure 5 Schematic presentation of the synthesis of keratin-incorporated bacterial cellulose. Data from Keskin Z et al. ${ }^{39}$ Abbreviations: A. xylinum, Acetobacter xylinum; BC, bacterial cellulose.

chemically sulfated or nonsulfated hyaluronan and CSA scaffolds were prepared by electrospinning method. ${ }^{41}$ Surface morphologies of nanofiber were not depended on amount and kinds of GAGs. In vitro release kinetics demonstrated that GAGs release is control by diffusion. The capability of this nanofiber was determined by human keratinocyte, fibroblast, and mesenchymal stem cell adhesion and proliferation tests. A noticeable enhancement in cell number was seen when cultivating all three cell types alone on scaffolds including nonsulfated hyaluronan and CSA. These results proposed that sulfated GAG nanocomposite could be a good candidate for the progression of progressed skin in tissue engineering. ${ }^{41}$

Based on same properties to the ECM, a prepared gelatin nanofiber by electrospinning method is a great potential for the applications in wound dressings and tissue engineering, but gelatin shows some limitation in application such as water solubility and weak mechanical strength. Gelatin was cross-linked in situ with 1,4-butanediol diglycidyl ether at different concentrations and incubation time points at $37^{\circ} \mathrm{C}$. The results of physical, chemical, and biological analyses of 1,4-butanediol diglycidyl ethercross-linked electrospun gelatin meshes indicated that by varying the concentration of 1,4-butanediol diglycidyl ether, morphologies, modulate fiber size, and mechanical power have been changed. Furthermore, the prepared nanofiber displayed no toxicity against fibroblasts, showing acceptable property of the prepared composition for skin tissue engineering. ${ }^{42}$

Skin scarring after significant dermal damages is an important medical problem, due to limited information about healing mechanisms. From the performed studies related to pathophysiological injuring, it was concluded that one of the most important reasons for weak healing is abnormal collagen reconstruction. In this field, a new synthesized scaffold composed of a collagen protein and a special GAG has been prepared by Jeon et al. The prepared composition is applied in a rat skin excisional model, which successfully treated initial wound scars by effective reepithelialization, neovascularization, and rapid collagen preparations. In addition, the regenerated dermal collagen scaffold has homogeneous size of collagen fibrils and ordered packing and contains a safe tissue component. Generally, the biosafety and new composite could be a great candidate for enhanced healing rate and high-quality and sufficient scar prevention. ${ }^{43}$ Figure 6 shows the schematic representation of synthesis of this novel collagen. ${ }^{43}$

Behind weak mechanical strength, low incorporation to native tissues and lack of antimicrobial properties hydrogels have been applied continually in tissue engineering. As an example, some sprayable, high mechanical strength, and biodegradable hydrogels, with antimicrobial ability, for the treatment of chronic wounds have been prepared. The nanocomposite was prepared using two 


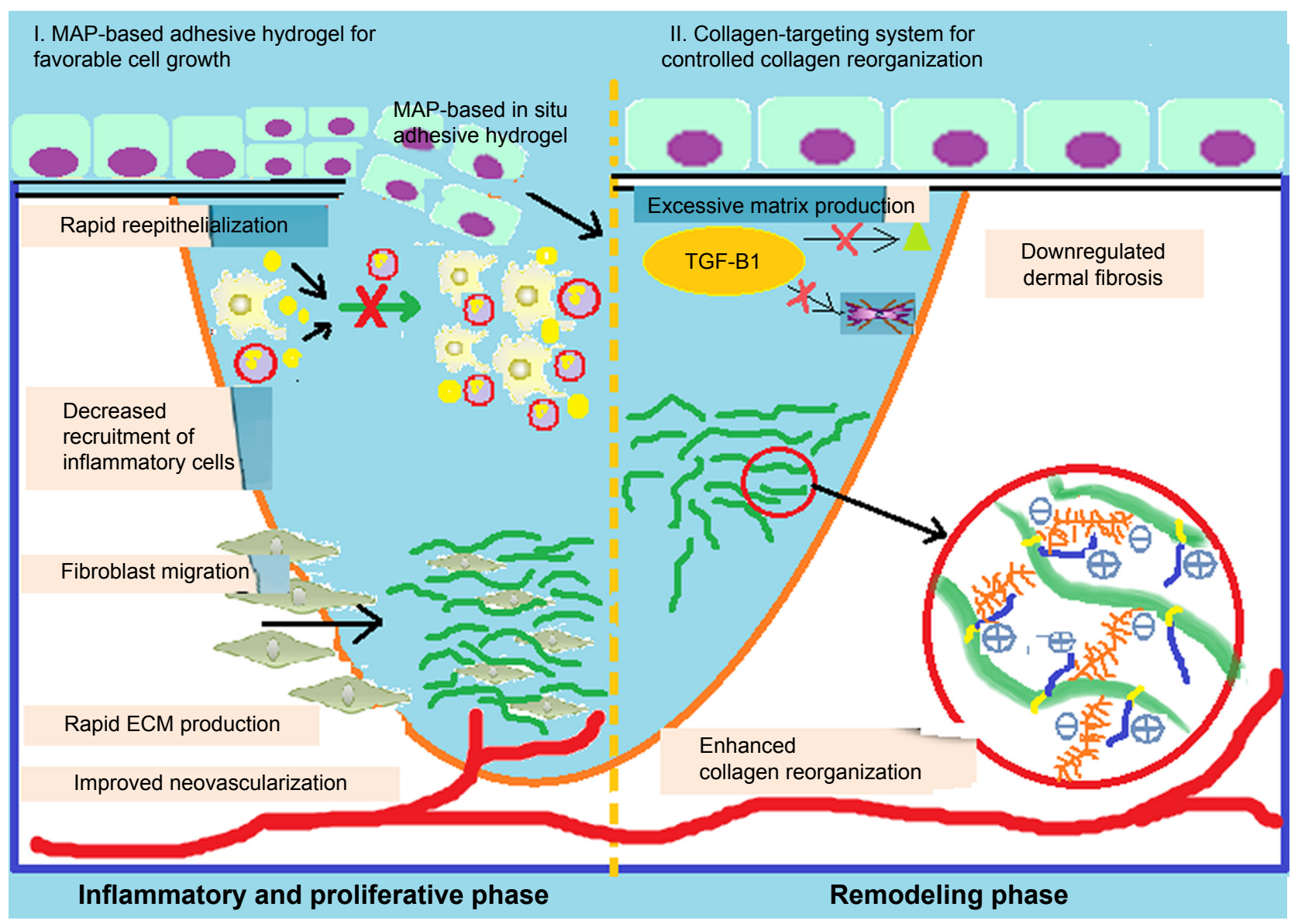

Figure 6 Schematic representation of the suggested mechanism for the treatment of skin scars. Data from Jeon EY et al. ${ }^{43}$ Abbreviations: ECM, extracellular matrix; MAP, microporous annealing particle.

ECM-derived biopolymers, gelatin methacryloyl (GelMA) and methacryloyl-substituted tropoelastin (MeTro), during visible light-induced cross-linking. Also, the inserted antimicrobial peptide Tet213 to the hydrogels showed antimicrobial activity against Gram (+) and (-) bacteria. The porosity, degradability, swellability, mechanical, and adhesive properties are affected by various ratios of MeTro/ GelMA and the final polymer concentration. The subcutaneous implantation of the composite in rats showed their biocompatibility and biodegradation in vivo. ${ }^{44}$ The schematic representation of preparing of hydrogel composite is given in Figure 7.

Although application of tissue regeneration has been clinically effective in the treatment of injured body organs, many problems such as the deficiency of resilience and mechanical power, donor-site morbidity, regular losing of volume, and fibrous capsular structure exist. These problems can be solved by utilizing bioabsorbable tissues with high resilience and large strains. ${ }^{45}$ Hence, the tridimensional tissues prepared by inserting water-based polyurethane (synthesized from polytetramethylene ether glycol, isophorone diisocyanate, and 2,2-bis[hydroxymethyl] butyric acid) into a bio-active ECM including small intestinal submucosa have been noticed to progress tissue engineering. ${ }^{45} \mathrm{After}$ analyzing the structure and properties of the prepared polyurethane/small intestinal submucosa, the strength, Young's modulus, and resilience of wet polyurethane/small intestinal submucosa samples were evaluated in comparison with crosslinked polyurethane. Furthermore, the ability to increase cell attachment and proliferation of the fabricated specimens was indicated using human umbilical vein endothelial cells. Consequently, the prepared polyurethane/small intestinal submucosa composition showed high resilience and significant cell viability without any cytotoxicity. ${ }^{45}$

Recently, the antibacterial properties, biocompatibility, and mechanical strength of PLLA/Ag nanocomposite prepared by electrospinning have been studied. The nanosilver solution was prepared by the biological reduction mechanism from silver nitrate $\left(\mathrm{AgNO}_{3}\right)$ and bitter gourd extract (reducing agent) in diphase system including a PLLA. The in vitro assay using Escherichia coli and Staphylococcus aureus by an agar disk diffusion method indicated that 
A
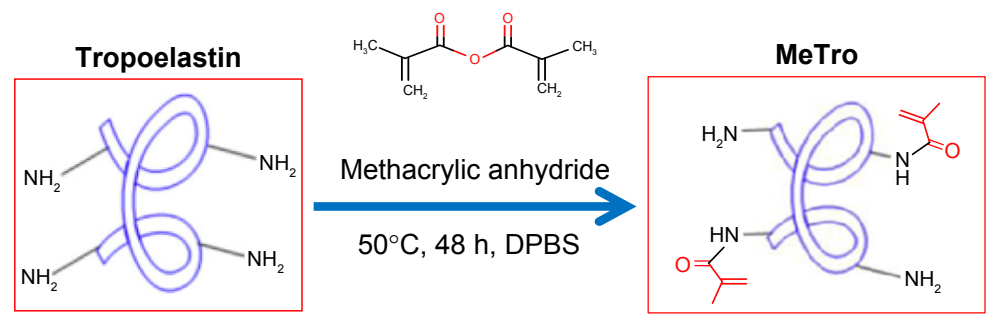

\section{C}

B

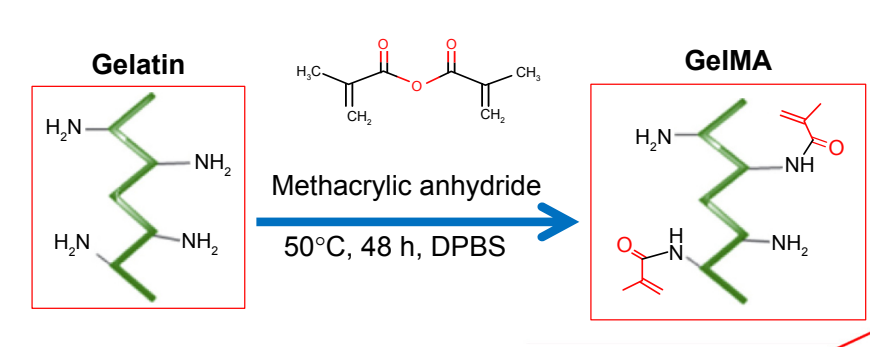

D
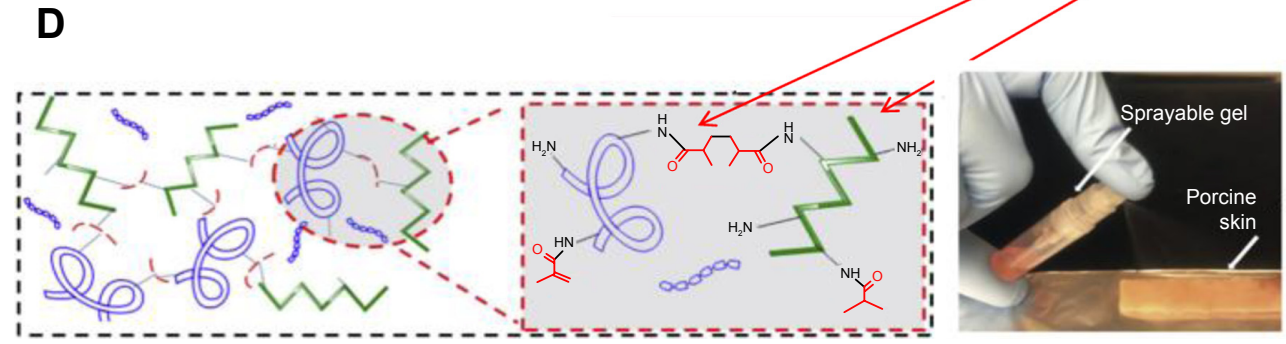

Figure 7 A schematic representation of the synthesis of different hydrogel composites: (A) MeTro, and (B) GelMA, and (C and D) MeTro-GelMA-AMP; AMP, GelMA, and MeTro were added to a TEA (coinitiator) and VC (coinitiator) solution. Data from Annabi $\mathrm{N}$ et al. ${ }^{44}$

Abbreviations: AMP, antimicrobial peptide; DPBS, Dulbecco's phosphate-buffered saline; GelMA, gelatin methacryloyl; MeTro, methacryloyl-substituted tropoelastin; TEA, triethanolamine; VC, poly(N-vinylcaprolactam).

the PLLA/Ag nanocomposite was also cytocompatible with fibroblasts and did not damage the cell growth. Based on the results, PLLA/Ag nanofibers as a safe wound healing material can increase the proliferation and ability of epidermal cells and fibroblasts. ${ }^{46}$ The application of green materials and green methods in skin tissue engineering is given in Table 3.

\section{Muscle tissue engineering}

The research of muscle tissue engineering includes the combined application of cells and scaffolds to treat the injured muscles. ${ }^{47,48} \mathrm{An}$ important subject in muscle tissue engineering is to generate functional scaffold similar to native muscle and have an ability to contract. ${ }^{49} \mathrm{~A}$ green approach is needed to produce scaffolds that are composed of biomaterials or naturally derived compounds (such as an ECM) by applying safe synthetic methods to provide a muscle tissue or muscle regenerative environment.

\section{Synthesized muscle tissue engineering}

Mimicking the nanofibrous structure and conductivity of the ECM for electrical distribution of the origin myocardium must be sufficient for cardiac scaffolds and cardiomyocyte (CM)-based bioactuators. CMs have intrinsic electroactivity property and can spontaneously show response against electrical signal. Therefore, to simulate the origin myocardium, biomaterials should contain ECM-liked nanofibrous

Table 3 Summary of applications of green materials and methods in skin tissue engineering

\begin{tabular}{|c|c|c|}
\hline Skin tissue & $\begin{array}{l}\text { Green chemistry } \\
\text { principle }\end{array}$ & Reference \\
\hline Beta vulgaris & $\begin{array}{l}\text { Less hazardous } \\
\text { chemical syntheses }\end{array}$ & 37 \\
\hline HEC/silver nanoparticles & $\begin{array}{l}\text { Ecofriendly and safer } \\
\text { solvents and auxiliaries }\end{array}$ & 38 \\
\hline Bacterial cellulose & $\begin{array}{l}\text { Ecofriendly and safer } \\
\text { solvents and auxiliaries }\end{array}$ & 39 \\
\hline $\begin{array}{l}\text { Polyester (PCL), a polysaccharide } \\
\text { (CS), and GEL }\end{array}$ & Atom economy & 40 \\
\hline $\begin{array}{l}\text { Gelatin/sulfated or nonsulfated } \\
\text { hyaluronan }\end{array}$ & Atom economy & 41 \\
\hline $\begin{array}{l}\text { Healing-inspired collagen } \\
\text { targeting glue }\end{array}$ & Atom economy & 43 \\
\hline $\begin{array}{l}\text { Gelatin methacryloyl/methacryloyl- } \\
\text { substituted recombinant human } \\
\text { tropoelastin/hydrogel }\end{array}$ & $\begin{array}{l}\text { Ecofriendly and safer } \\
\text { solvents and auxiliaries }\end{array}$ & 44 \\
\hline $\begin{array}{l}\text { Polyurethane/small intestinal } \\
\text { submucosa }\end{array}$ & $\begin{array}{l}\text { Product with lower } \\
\text { cytotoxicity }\end{array}$ & 45 \\
\hline PLA/Ag nanofibers & $\begin{array}{l}\text { Designing safer } \\
\text { chemicals }\end{array}$ & 46 \\
\hline
\end{tabular}

Abbreviations: CS, chitosan; GEL, gelatin; HEC, hydroxyethyl cellulose; PCL, polycaprolactone; PLA/Ag, polylactic acid/silver. 
structures and electrical conductivity to let electrical transmission. However, there is still discussion for preparing such proper materials for cardiac tissue engineering and $\mathrm{CMs}$ based bioactuators. Due to the coupling of two important properties recently, nanofibrous structures made of PLLA and polyaniline for cardiac tissue engineering and CM-based 3D bioactuators have been reported. The nontoxicity and ability of PLLA enhances the use of this biomaterial in tissue engineering because of regeneration on large quantity with necessary power of strength, degradation rate, and structure. These PLLA/polyaniline conductive nanocompounds displayed great cell viability and increased the differentiation of $\mathrm{H} 9 \mathrm{c} 2$ cardiomyoblasts in terms of the maturation index and fusion index. Moreover, PLLA/polyaniline nanofibrous sheets increased cell-cell interactions, maturation and automatic beating frequency of primary CMs and similar to the ECM show a significant source in cardiac tissue engineering and CM-based 3D bioactuators. ${ }^{50}$

A bilayered CS-gelatin composite, with acceptable morphological and mechanical properties and controlled swelling and biodegradation, was recently applied as a biological blood vessel. The porous layer showed a big surface area, good cell adhesion and proliferation, and the second nonporous layer displays the inhibition against cells and gives the enhanced flexibility and elasticity to the nanocomposites. Fibroblast cell proliferation on the prepared scaffold showed the biodegradability vs time, allowing cells to propagate into the tissue network. Based on the obtained results, the designed bilayered composite with great physiochemical, mechanical, and biological properties could be a sufficient candidate for blood..$^{51}$ Figure 8 shows the synthesis of the bi-layered CS-gelatin composite using particulate leaching.

Gellan gum (GG) spongy-like hydrogels (SLH) with porous structure, high mechanical strength, and cell performance have shown great responses for soft tissue engineering applications. Due to the natural properties of GG-SLH and polypyrrole (PPy) electroactivity, a conductive $\mathrm{PPy}-$ GG-SLH for applying in muscle scaffold was proposed. PPy-GG-SLH shows compressive modulus and recovering capacity more than GG-SLH. However, the mechanical strength of PPy-GG-SLH is weak. PPy-GG-SLH did not show any cytotoxicity against L929 cells and L929 and C2C12 myoblast cells. ${ }^{52}$

It is very important propagation electrical conductive and flexible green materials to prepare the elastic scaffold and to arrange cell manner during scaffold treatment. To conquer this problem, different and new electrical conductive and degradable polyurethane-urea copolymers with elastomeric properties were prepared using an amine-capped

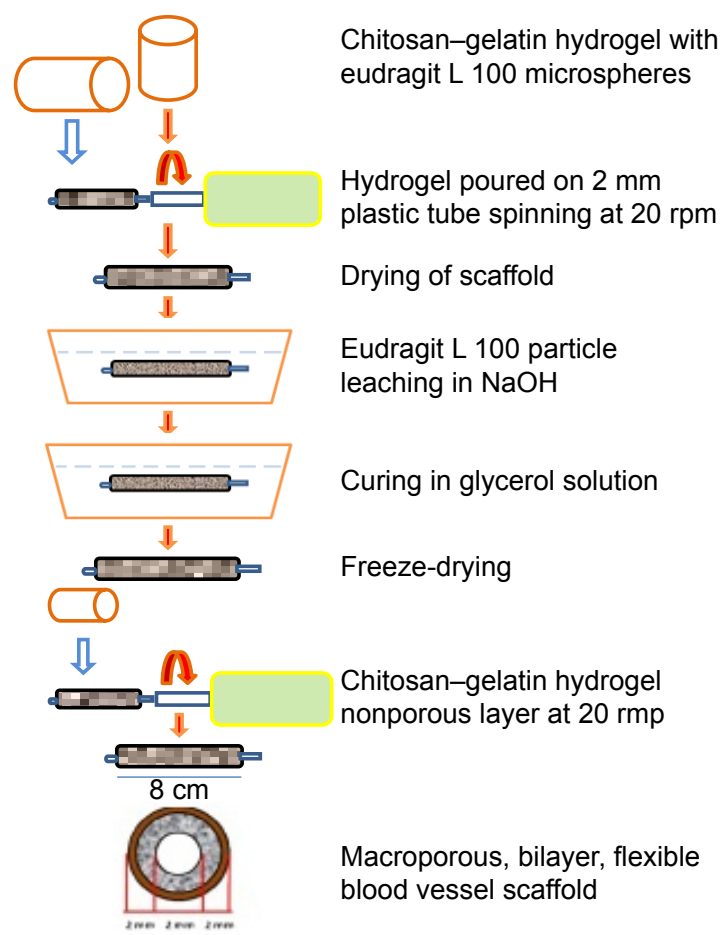

Figure 8 Synthesis of bi-layered chitosan-gelatin composite using particulate leaching. Data from Badhe RV et al. ${ }^{51}$

aniline trimer, dimethylol propionic acid, polylactide, and hexamethylene diisocyanate. ${ }^{53}$ These compounds are great potential for the treatment or regeneration of elastic tissues same as skeletal muscle, cardiac muscle, and nerve.

Recently, core-shell nanofibers with many adequate biocompatible and mechanical properties have been used as new materials in preparation of different tissues. Nanofibrous, composed of a polycaprolactone core and a functionalized gelatin shell, was synthesized by coaxial electrospinning and photo crosslinking technique for vascular tissue regeneration. ${ }^{54}$ The medical efficiency of the nanofibrous was measured by analyzing chemical, physical, and biocompatibility properties. The obtained results displayed that the nanofibers with a higher amount of gelatin also showed lower water contact angles and higher hydrophilicities. These valuable findings are very important when the prepared nanofibers are in contact with blood and normal human dermal fibroblasts. Inserting gelatin into the nanofibers reduced the water contact angles and increased the hydrophilicity of the composition. Furthermore, the gelatin used in the nanofibers also increased their applicability due to the decreasing hemolytic and thrombogenic properties of the compounds. ${ }^{54}$

\section{Natural compound-based muscle tissue engineering}

Several recent researches have been directed toward the development of green chemistry methods with a focus on 
biocatalysis and biobased materials. ${ }^{3}$ Extracellular matrices of xenogeneic origin have been extensively applied for medical uses, regardless of their heterogenic characteristics. Surface functionalization of biomaterials using nanoparticles is an important method for modifying surface homogeneity in sophisticated tissue engineering. Recently, researchers indicated many different positive points of the cholecyst-obtained ECM (C-ECM) as a tissue engineering in comparison with extracellular matrices gained from other the body parts, such as the jejunum and urinary bladder. ${ }^{49}$ The application of gold nanoparticles (AuNPs) with large surface area-to-volume ratio onto the $\mathrm{C}$-ECM has been used to surface modification in cardiac tissue engineering. In this research, AuNPs were prepared, functionalized, and coupled with a porcine cholecystic ECM scaffold. The modified scaffold could be a great potential for the progression of cardiomyoblasts. Also, the nontoxic and green structure of the prepared scaffold was displayed by direct contact cytotoxicity testing and live/dead staining. Results indicated that the modified C-ECM has a great potential for cardiac tissue engineering to establish the bioactivity of the bionanocomposite tissue as a cardiac patch for restoring heart muscle injury. ${ }^{55}$

Recently, CS/GO nanocomposite with self-adhesive and self-healing properties and electroactivity was produced by the application of mussel-inspired protein polydopamine (PDA). ${ }^{56}$ Surface incorporation of polymerized dopamine is an easy, nontoxic, effective, and cost-saving alternative method to solve some problems of different tissue engineering. Reduced GO by PDA and incorporated into the hydrogel network to generate electric property. Good degradability, physical strength, acceptable adhesiveness, self-healing, and regeneration ability are due to different interactions between $\mathrm{CS} / \mathrm{GO}$ nanocomposites. Cell culture analysis confirmed that the electroactive CS/GO nanofiber increased cell viability and proliferation of human embryonic stem cell-derived fibroblasts (HEF1) and CMs in comparison with CS-PDA hydrogels. ${ }^{56}$ Figure 9 shows the activity of conductive $\mathrm{CS} / \mathrm{GO}$ nanofiber with a rapid selfhealing and regeneration behavior for tissue engineering.

At present, the artificial vascular muscles are made of synthetic materials that are prone to clot, infection, and other problems. These grafts in the laboratory produce a combination of living and biological cells and produce little side effects, but living tissues do not have a high stability for the permanent use of these grafts and can be produced if they are not produced from their own cells. For example, swine iPSC (siPSC) lines were produced by the incorporation of doxycycline-inducible reprogramming factors into fetal fibroblasts taken from a line of inbred miniature swine that does not reject by tissue and organ transplants or infection. Modified VSMCs were derived from siPSCs by the application of ascorbic acid and deactivation of the reprogramming factor via doxycycline withdrawal. Moreover, siPSC VSMCs incorporated polyglycolic acid (PGA) tissue easily constructed vascular tissues, which were inserted subcutaneously into immunodeficient mice and displayed further maturation showed by the expression of the mature VSMC marker, smooth muscle myosin heavy chain. Also, using a robust cellular self-assembly method,

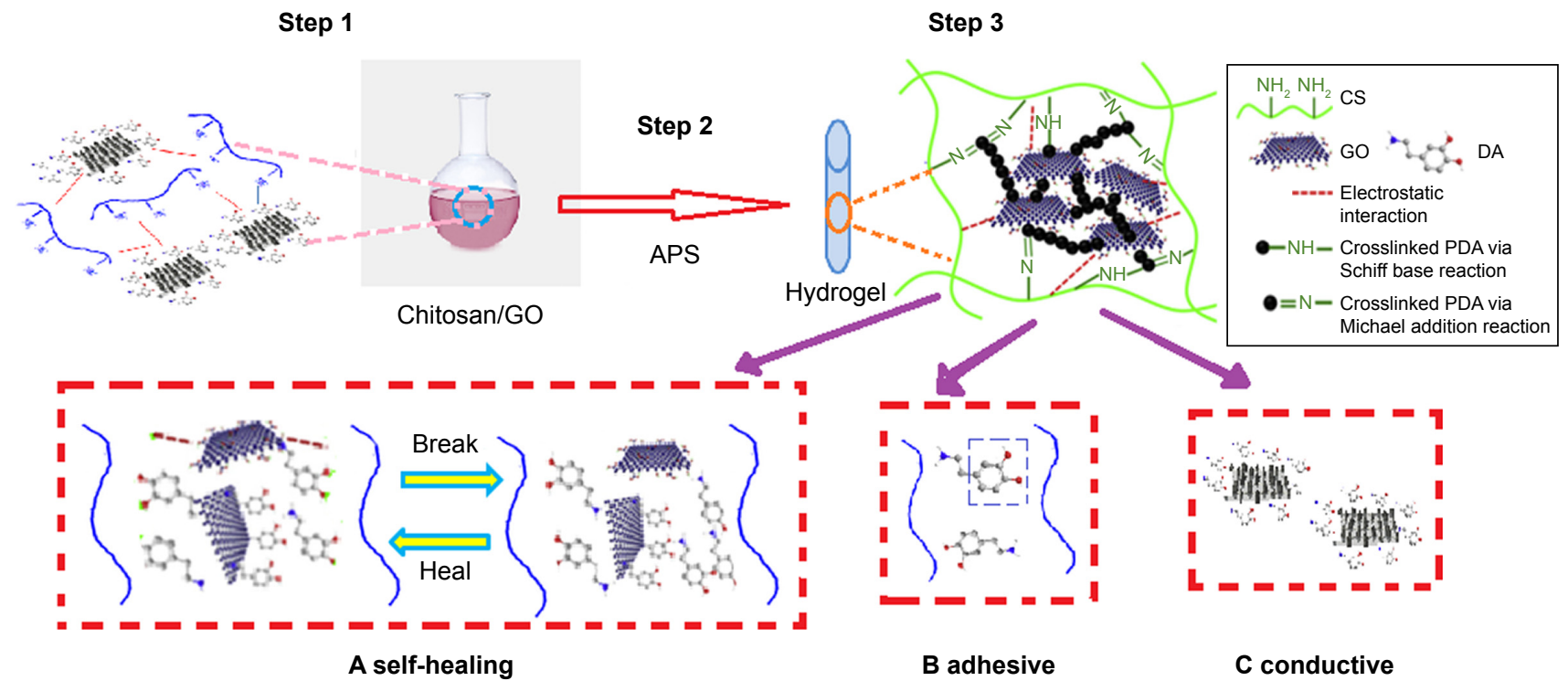

Figure 9 Mechanism of mussel-inspired conductive CS/GO nanofiber for tissue engineering. Data from Jing $X$ et al..$^{56}$ Abbreviations: APS, ammonium persulfate; CS, chitosan; GO, graphene oxide; PDA, polydopamine. 
the prepared 3D scaffold-free tissue rings from siPSC VSMCs showed great mechanical power and contractile activity to those changed from swine primary VSMCs. These prepared vascular constructs, from doxycycline-inducible inbred siPSCs, suggested a novel potential approach for the preclinical determination of autologous human iPSC-based vascular tissues. ${ }^{57}$

One of the most important subjects in tissue engineering is losing the functionality of skeletal muscle progenitor cell after separation from alive tissues and moving to culture dishes, due to the lack of an ECM. Recently, a new material was developed to increase the propagation and differentiation of human muscle tissue progenitor cells in vitro with skeletal muscle ECM in composition with a changed alginate hydrogel incorporated with gelatin and heparin (Alg-G-H) as a substrate. ${ }^{58}$ This $\mathrm{Alg}-\mathrm{G}-\mathrm{H}$ substrate, together with skeletal muscle ECM, importantly increased cell expansion, differentiation, and maturation of human skeletal muscle progenitor cells in comparison with basic substrate. This method could be a beneficial tool for in vitro skeletal muscle cell differentiation and maturation, with great promising uses in tissue production. ${ }^{58}$

Table 4 shows some examples of the application of safe, green materials in muscle tissue engineering.

\section{Neural tissue engineering}

Neural tissue engineering is a special branch of tissue engineering, including methods to remove inflammation and fibrosis upon implantation of foreign material into the nervous system. The requirement for neural tissue engineering is due to the difficulty of the nerve cells and neural tissues to prepare on their own after neural injury. ${ }^{59}$

Myelination of Schwann cells (SCs) is very important for the nervous tissue preparation and materials that can be prepared from SCs as tissues. The application of polyurethane by the polycondensation of poly(glycerol sebacate) and aniline pentamer to importantly regenerate SC myelin gene expression and neurotrophin secretion is another example of a green compound in nerve tissue engineering. ${ }^{60}$ The synthesis of neurotrophin secretion from SCs on conductive films have been determined by measuring the dependence of intracellular $\mathrm{Ca}^{2+}$ levels and $\mathrm{SC}$ myelination. These results proposed that electroactive and biodegradable polyurethanes have an acceptable potential for nerve tissue engineering. ${ }^{60}$

Green and safe systems for generating SCs are another example for the treatment of peripheral nerve damages. Pan et $\mathrm{al}^{61}$ determined that the peripheral blood-derived mesenchymal stem cells (PBMSCs) could be inspired into SC-like cells, displaying SC-specific markers and functional parameters. Application of induced PBMSCs (iPBMSCs) for the treatment of injured rat sciatic nerves shows acceptable results and suggested that the prepared composed scaffold can treat a wrap in a sciatic nerve to nerve maintain, axonal restore, and remyelination, nerve conduction in the target muscle. ${ }^{61}$

Peripheral nerve damages have attracted major concerns in tissue engineering for long time. Biocompatible and biodegradable CS has been frequently applied as a safe material in green tissue preparation. ${ }^{62}$ Envisioning its uses in peripheral nerve preparation, one study prepared CS membranes with three different degrees of acetylation. The three-acetylated CS membranes were analyzed, and the results confirmed smooth, flat surface, higher roughness, surface energy, and same biodegradability. All the prepared composites show great mechanical strength and did not show any calcification in a simulated body fluid test. ${ }^{62}$

Parkinson's disease (PD) is a brain disorder that causes gradual loss of muscle control. The signs and symptoms of PD are mild initially and may occasionally be overlooked. ${ }^{63} \operatorname{In} 2015$, PD influenced 6.2 million people and about 117,400 deaths globally have been occurred. PD typically occurs in human older than 60 years, or $1 \%$ of human population. Despite the

Table 4 Examples of some safe and green materials for muscle tissue engineering

\begin{tabular}{lll}
\hline Muscle tissue material & Green chemistry principle & Uses \\
\hline Poly(L-lactic acid)/polyaniline & Ecofriendly and safer solvents and auxiliaries & Cardiac tissue engineering \\
CS-gelatin composite & Enhance the mechanical and biological properties & Macroporous blood vessel scaffold \\
Gellan gum & Ecofriendly and safer solvents and auxiliaries & Skeletal muscle \\
Polyurethane-urea & Enhance the mechanical properties & Skeletal muscle, cardiac muscle \\
PCL-functionalized gelatin nanofiber & Biocompatibility and biodegradation & Blood vessel scaffold \\
Cholecyst-derived extracellular & Ecofriendly and safer solvents and auxiliaries & Skeletal muscle \\
matrix/Au nanoparticles & & 53 \\
CS/GO composite & Biocompatibility and biodegradation & 54 \\
Alg-G-H composition & Cost-effective tool & Skeletal muscle \\
\hline
\end{tabular}

Abbreviations: Alg-G-H, alginate hydrogel incorporated with gelatin and heparin; CS, chitosan; GO, graphene oxide; PCL, polycaprolactone. 
noticeable attempt related to cure PD, a successful medical method is not sufficient. In the PD treatment, bone marrowderived mesenchymal stem cells (BMSCs) were genetically designed to overcome the neurotrophin-3 (nt-3) gene that inhibits central nervous system and activated like neuronal differentiation of BMSCs. ${ }^{63}$ PLGA microcarriers were modified as a proper tissue and prepared by double emulsion method. The surface of PLGA microcarriers was modified by collagen as a bioadhesive factor for enhanced cell attachment. The results indicated sufficient overexpression of neurotrophin-3, and the expression of tyrosine hydroxylase in transfected BMSCs showed that neurotrophin-3 promoted the intracellular signaling pathway of dopaminergic neuron differentiation. The use of dopamine in the peripheral media of the cell/ microcarrier complex showed that BMSCs successfully differentiated into dopaminergic neurons. The sustained presence of growth factors suggests that this therapy could be applied as a new therapeutic method for the treatment of PD. ${ }^{63}$ Figure 10 shows the schematic representation of preparation method of coupling neurotrophin-3-overexpressing marrow-derived mesenchymal stem cells and PLGA microcarriers for the treatment of PD.

A composition of silk fibroin/silk sericin nerve with same structural properties can be used as native peripheral nerve fasciculi. ${ }^{64}$ However, their mechanical strength is not sufficient. Recently, nerve conduits with a new and bionic structure with dual layers have been reported. The significant feature of these nerve conduits is that the multiwalled silk fibroin/silk sericin conduits with bionic character like to the native structure of the peripheral nerve fasciculi, which is sufficient for nerve restore, and the outer layer (the hollow PLGA conduits) could show higher mechanical strength for the internal skeleton. The double layer composition was modified and incorporated into the hollow PLGA sheath lumen and then was used as a bridge across the sciatic nerve lack in rats. The results of peripheral nerve treatment and postimplantation show that the new PLGA-coated silk fibroin/silk sericin nerve conduits could apply for the nerve regeneration and treatment of nerve damages. ${ }^{64}$

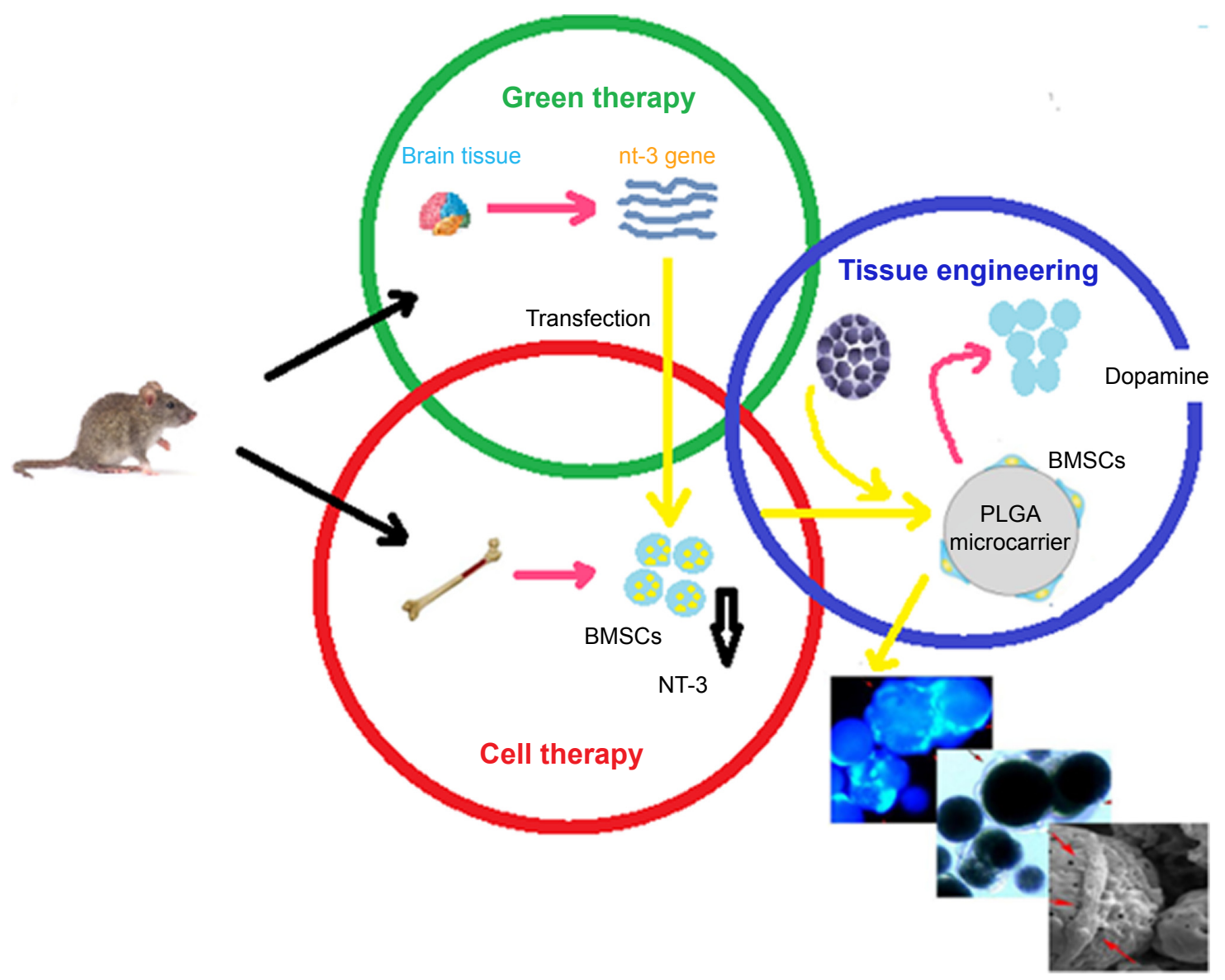

Figure 10 Schematic representation of the preparation method of coupling neurotrophin-3-overexpressing MSCs and PLGA microcarriers for PD treatment. Data from Moradian $\mathrm{H}$ et al. ${ }^{63}$

Abbreviations: BMSCs, bone marrow-derived mesenchymal stem cells; MSCs, marrow-derived mesenchymal stem cells; PD, Parkinson's disease; PLGA, poly(lactic-coglycolic acid). 


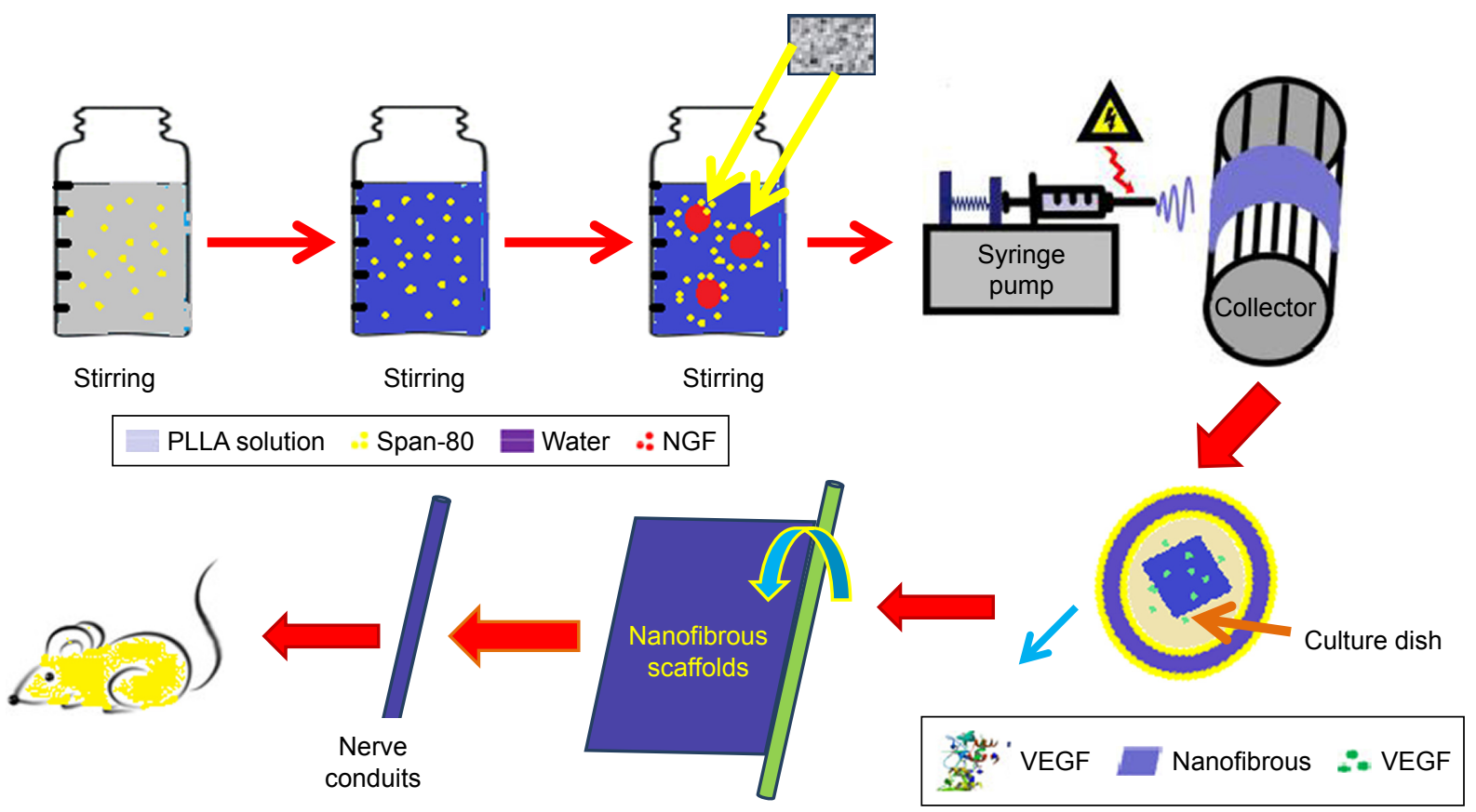

Figure I I Schematic illustration of the preparation process of core-shell nanofibrous scaffolds for sciatic nerve regeneration. Data from Xia B et al. ${ }^{66}$ Abbreviations: NGF, nerve growth factor; PLLA, poly(L-lactic acid); VEGF, vascular endothelial growth factor.

Two-dimensional monolayer culture is the usual cell culture technique, ${ }^{65}$ but the cells may miss the functionality in the in vivo condition due to the difference between the two environments. As an applicable material, Nagai et $\mathrm{al}^{65}$ prepared an in vivo environment to gain cell responses based on collagen and heparin (Hep-col) that could immobilize growth factors, which is necessary for ECM activity. Neural stem/progenitor cells cultured in the Hep-col gel grew and differentiated more actively than in collagen, showing an in vivo environment in the Hep-col gel. Also, results point out that the neural cells cultured in the present research had synaptic connections and neuronal action activity by immunofluorescence staining and $\mathrm{Ca} 2 \mathrm{D}$ imaging. ${ }^{65}$ The presented method is an environmentally friendly, cost-effective, and green way to culture neural cells using natural compounds.

The designed and programmed delivery of multiple therapeutic agents is very important to reduce nerve malfunction for nerve injury. ${ }^{66}$ Recombinant human vascular endothelial growth factor (VEGF) and recombinant human nerve growth factor (NGF) incorporated on the surface and in the core of PLLA nanofibrous using electrospinning technique by Xia and Lv. The in vitro assay tests indicated that VEGF and NGF had a consecutive release pattern while most of the VEGF was released for the short time but the NGF could be continuously released for $>1$ month. This tissue could increase the neural differentiation of inspired pluripotent stem cells derived neural crest stem cells in vitro.
Also, this nanofibrous was used to a critically sized lack in a rat sciatic nerve model. Footprint analysis, electrophysiological tests, and histological analysis showed a noticeable treatment of neovascularization as well as nerve healing after 3 months postoperation. Results indicated that green VEGF and NGF in an electrospun nanofibrous composed had a great and safe candidate with synergistic properties on the restoration of vascularized nerve tissue. ${ }^{66}$ Figure 11 shows a schematic representation of the synthesis of core-shell nanofibrous scaffolds for sciatic nerve restoration.

\section{Conclusion}

In the present research, we have showed that the aim of many researches is to develop the application of sustainable, low-energy, or low-cost processes for the manufacturing of different tissues and reduce the consumption of toxic materials. For example, application of extracted natural compounds from plants or skeletons of animals same as polysaccharides or some complex proteins are some of the safe method to engineer tissues and organs. Certainly, the new components and composites as well as the improvement and replacement of organs and tissues would provide a major relief for many patients suffering from kidney disease. In future, the focuses of research will be based on the preparation of natural polymers, bioglasses, and nanocomposites with special properties for tissue treatment or regeneration. It also aims to progress biomaterials for minimally invasive 
surgery and conquer to bad signs for injectable formulations such as degradability, injectability, and mechanical strength. Preventing these problems will have a significant effect on the application of prepared scaffolds and tissues in the treatment or restoration of injured body organs.

\section{Acknowledgment}

The authors would like to acknowledge Ilam University, Ilam, Iran, and Northeastern University (NEU), Boston, MA, USA, for their earnest cooperation of this research.

\section{Disclosure}

The authors report no conflicts of interest in this work.

\section{References}

1. Iravani A, Akbari MH, Zohoori M. Advantages and Disadvantages of Green Technology; Goals, Challenges and Strengths. Int J Sci Eng Appl. 2017;6(9):272-284.

2. Whitney GA, Jayaraman K, Dennis JE, Mansour JM. Scaffold-free cartilage subjected to frictional shear stress demonstrates damage by cracking and surface peeling. J Tissue Eng Regen Med. 2017;11(2):412-424.

3. Macarthur BD, Oreffo RO. Tissue engineering: mathematical models are helping to take tissue engineering from concept to reality. Nature. 2005;433(19):19-20.

4. Cassidy JW. Nanotechnology in the Regeneration of Complex Tissues. Bone Tissue Regen Insights. 2014;5:25-35.

5. Nam YS, Park TG, Yoon Sung N, Tae Gwan P. Biodegradable polymeric microcellular foams by modified thermally induced phase separation method. Biomaterials. 1999;20(19):1783-1790.

6. Ko HF, Sfeir C, Kumta PN. Novel synthesis strategies for natural polymer and composite biomaterials as potential scaffolds for tissue engineering. Philos Trans A Math Phys Eng Sci. 2010;368(1917):1981-1997.

7. Melchels F, Wiggenhauser PS, Warne D, et al. CAD/CAM-assisted breast reconstruction. Biofabrication. 2011;3(3):034114.

8. Elisseeff J, Px M. Scaffolding in Tissue Engineering. Boca Raton: CRC; 2005.

9. Lee GY, Kenny PA, Lee EH, Bissell MJ. Three-dimensional culture models of normal and malignant breast epithelial cells. Nat Methods. 2007;4(4):359-365.

10. Lai Y, Asthana A, Kisaalita WS. Biomarkers for simplifying HTS 3D cell culture platforms for drug discovery: the case for cytokines. Drug Discov Today. 2011;16(7-8):293-297.

11. Wang YX, Robertson JL, Spillman WB, Claus RO. Effects of the chemical structure and the surface properties of polymeric biomaterials on their biocompatibility. Pharm Res. 2004;21(8):1362-1373.

12. Black CR, Goriainov V, Gibbs D, Kanczler J, Tare RS, Oreffo RO. Bone Tissue Engineering. Curr Mol Biol Rep. 2015;1(3):132-140.

13. Junqueira LC, Carneiro J, Foltin J, et al. Basic Histology, Text \& Atlas (10th ed). New York City, NY: McGraw-Hill Companies; 2003:144.

14. Khajuria DK, Vasireddi R, Trebbin M, Karasik D, Razdan R. Novel therapeutic intervention for osteoporosis prepared with strontium hydroxyapatite and zoledronic acid: In vitro and pharmacodynamic evaluation. Mater Sci Eng C Mater Biol Appl. 2017;1(71):698-708.

15. Khajuria DK, Disha C, Vasireddi R, Razdan R, Mahapatra DR. Risedronate/zinc-hydroxyapatite based nanomedicine for osteoporosis. Mater Sci Eng C Mater Biol Appl. 2016;63:78-87.

16. Khajuria DK, Razdan R, Mahapatra DR, Development MDR. Development, in vitro and in vivo characterization of zoledronic acid functionalized hydroxyapatite nanoparticle based formulation for treatment of osteoporosis in animal model. Eur J Pharm Sci. 2015;66:173-183.
17. Zhou Y, Yao H, Wang J, Wang D, Liu Q, Li Z. Greener synthesis of electrospun collagen/hydroxyapatite composite fibers with an excellent microstructure for bone tissue engineering. Int J Nanomedicine. 2015;10(1):3203-3215.

18. D'Agostino A, Trevisiol L, Favero V, et al. Hydroxyapatite/Collagen Composite Is a Reliable Material for Malar Augmentation. J Oral Maxillofac Surg. 2016;74(6):1238.e1-121238.e1.

19. Murugan S, Rajan M. Greener Synthesis of Nano Hydroxyapatite using Fatty acids template for the application of Tissue Engineering Nano Hydroxyapatite: Fatty acids Synthesis and Characterizations. J Mol Pharm Org Process Res. 2017;05(01):1-4.

20. Ingole VH, Hany Hussein K, Kashale AA, et al. Ultrasound-assisted green economic synthesis of hydroxyapatite nanoparticles using eggshell biowaste and study of mechanical and biological properties for orthopedic applications. J Biomed Mater Res A. 2017;105(11):2935-2947.

21. Jiang L, Li Y, Xiong C, Su S, Ding H. Preparation and Properties of Bamboo Fiber/Nano-hydroxyapatite/Poly(lactic-co-glycolic) Composite Scaffold for Bone Tissue Engineering. ACS Appl Mater Interfaces. 2017;9(5):4890-4897.

22. Hu Y, Chen J, Fan T, et al. Biomimetic mineralized hierarchical hybrid scaffolds based on in situ synthesis of nano-hydroxyapatite/chitosan/ chondroitin sulfate/hyaluronic acid for bone tissue engineering. Colloids Surf B Biointerfaces. 2017;157(157):93-100.

23. Xu S, Liu J, Zhang L, Yang F, Tang P, Wu D. Effects of HAp and TCP in constructing tissue engineering scaffolds for bone repair. J Mater Chem B. 2017;5(30):6110-6118.

24. Heidari F, Razavi M, E Bahrololoom M, et al. Mechanical properties of natural chitosan/hydroxyapatite/magnetite nanocomposites for tissue engineering applications. Mater Sci Eng C Mater Biol Appl. 2016;65:338-344.

25. Khajuria DK, Zahra SF, Razdan R. Effect of locally administered novel biodegradable chitosan based risedronate/zinc-hydroxyapatite intrapocket dental film on alveolar bone density in rat model of periodontitis. J Biomater Sci Polym Ed. 2018;29(1):74-91.

26. Lowe B, Venkatesan J, Anil S, Shim MS, Kim SK. Preparation and characterization of chitosan-natural nano hydroxyapatite-fucoidan nanocomposites for bone tissue engineering. Int J Biol Macromol. 2016; 93(Pt B):1479-1487(Pt B).

27. Cui H, Liu Y, Deng M, et al. Synthesis of biodegradable and electroactive tetraaniline grafted poly(ester amide) copolymers for bone tissue engineering. Biomacromolecules. 2012;13(9):2881-2889.

28. Moeini S, Mohammadi MR, Simchi A. In-situ solvothermal processing of polycaprolactone/hydroxyapatite nanocomposites with enhanced mechanical and biological performance for bone tissue engineering. Bioact Mater. 2017;2(3):146-155.

29. Wang C, Zhao Q, Wang M. Cryogenic 3D printing for producing hierarchical porous and rhBMP-2-loaded Ca-P/PLLA nanocomposite scaffolds for bone tissue engineering. Biofabrication. 2017;9(2):025031.

30. Yang J, Yang X, Wang L, et al. Biomimetic nanofibers can construct effective tissue-engineered intervertebral discs for therapeutic implantation. Nanoscale. 2017;9(35):13095-13103.

31. Sell SA, Wolfe PS, Garg K, Mccool JM, Rodriguez IA, Bowlin GL. The Use of Natural Polymers in Tissue Engineering: A Focus on Electrospun Extracellular Matrix Analogues. Polymers. 2010;2(4):522-553.

32. Munarin F, Guerreiro SG, Grellier MA, et al. Pectin-based injectable biomaterials for bone tissue engineering. Biomacromolecules. 2011; 12(3):568-577.

33. Zhang F, Song Q, Huang X, et al. A Novel High Mechanical Property PLGA Composite Matrix Loaded with Nanodiamond-Phospholipid Compound for Bone Tissue Engineering. ACS Appl Mater Interfaces. 2016;8(2):1087-1097.

34. Tahriri M, Moztarzadeh F, Tahriri A, et al. Evaluation of the in vitro biodegradation and biological behavior of poly(lactic-coglycolic acid)/nano-fluorhydroxyapatite composite microspheresintered scaffold for bone tissue engineering. J Bioact Compat Polym. 2017;33(2):146-159. 
35. Lu W, Lu C, Li Y, Wu F, Zhao B, Dong X. Green fabrication of porous silk fibroin/graphene oxide hybrid scaffolds for bone tissue engineering. RSC Adv. 2015;5(96):78660-78668.

36. Johari N, Madaah Hosseini HR, Samadikuchaksaraei A. Optimized composition of nanocomposite scaffolds formed from silk fibroin and nano-TiO ${ }_{2}$ for bone tissue engineering. Mater Sci Eng C Mater Biol Appl. 2017;79:783-792.

37. Ranjbarvan P, Mahmoudifard M, Kehtari M, et al. Natural compounds for skin tissue engineering by electrospinning of nylon-beta vulgaris ASAIO J. 2017.

38. Zulkifli FH, Hussain FSJ, Zeyohannes SS, Rasad M, Yusuff MM. A facile synthesis method of hydroxyethyl cellulose-silver nanoparticle scaffolds for skin tissue engineering applications. Mater Sci Eng C. 2017;79:151-160.

39. Keskin Z, Sendemir Urkmez A, Hames EE. Novel keratin modified bacterial cellulose nanocomposite production and characterization for skin tissue engineering. Mater Sci Eng C Mater Biol Appl. 2017;75: 1144-1153.

40. Gomes S, Rodrigues G, Martins G, Henriques C, Silva JC. Evaluation of nanofibrous scaffolds obtained from blends of chitosan, gelatin and polycaprolactone for skin tissue engineering. Int J Biol Macromol. 2017; 102:1174-1185

41. Bhowmick S, Rother S, Zimmermann $\mathrm{H}$, et al. Biomimetic electrospun scaffolds from main extracellular matrix components for skin tissue engineering application - The role of chondroitin sulfate and sulfated hyaluronan. Mater Sci Eng C. 2017;79:15-22.

42. Dias JR, Baptista-Silva S, De Oliveira CMT, et al. In situ crosslinked electrospun gelatin nanofibers for skin regeneration. Eur Polym J. 2017;95:161-173.

43. Jeon EY, Choi BH, Jung D, Hwang BH, Cha HJ. Natural healinginspired collagen-targeting surgical protein glue for accelerated scarless skin regeneration. Biomaterials. 2017;134:154-165.

44. Annabi N, Rana D, Shirzaei Sani E, et al. Engineering a sprayable and elastic hydrogel adhesive with antimicrobial properties for wound healing. Biomaterials. 2017;139:229-243.

45. da L, Gong M, Chen A, et al. Composite elastomeric polyurethane scaffolds incorporating small intestinal submucosa for soft tissue engineering. Acta Biomater. 2017;59(59):45-57.

46. Alippilakkotte S, Kumar S, Sreejith L. Fabrication of PLA/Ag nanofibers by green synthesis method using Momordica charantia fruit extract for wound dressing applications. Colloids Surf A Physicochem Eng Asp. 2017;529(20):771-782.

47. Vandusen KW, Syverud BC, Williams ML, Lee JD, Larkin LM. Engineered skeletal muscle units for repair of volumetric muscle loss in the tibialis anterior muscle of a rat. Tissue Eng Part A. 2014;20(21-22): 2920-2930.

48. Shaffer F, Neblett R. Practical Anatomy and Physiology: The Skeletal Muscle System. Biofeedback. 2010;38(2):47-51.

49. Choi YS, Vincent LG, Lee AR, et al. The alignment and fusion assembly of adipose-derived stem cells on mechanically patterned matrices. Biomaterials. 2012;33(29):6943-6951.

50. Wang L, Wu Y, Hu T, Guo B, Ma PX, Px M. Electrospun conductive nanofibrous scaffolds for engineering cardiac tissue and $3 \mathrm{D}$ bioactuators. Acta Biomater. 2017;59(59):68-81.
51. Badhe RV, Bijukumar D, Chejara DR, et al. A composite chitosangelatin bi-layered, biomimetic macroporous scaffold for blood vessel tissue engineering. Carbohydr Polym. 2017;157(157):1215-1225.

52. Berti FV, Srisuk P, da Silva LP, Marques AP, Reis RL, Correlo VM. Synthesis and Characterization of Electroactive Gellan Gum SpongyLike Hydrogels for Skeletal Muscle Tissue Engineering Applications. Tissue Eng Part A. 2017;23(17-18):968-979.

53. Chen J, Dong R, Ge J, Guo B, Ma PX, Biocompatible MPX. Biocompatible, Biodegradable, and Electroactive Polyurethane-Urea Elastomers with Tunable Hydrophilicity for Skeletal Muscle Tissue Engineering. ACS Appl Mater Interfaces. 2015;7(51):28273-28285.

54. Coimbra P, Santos P, Alves P, et al. Coaxial electrospun PCL/ Gelatin-MA fibers as scaffolds for vascular tissue engineering. Colloids Surf B Biointerfaces. 2017;159(159):7-15.

55. Nair RS, Ameer JM, Alison MR, Anilkumar TV. A gold nanoparticle coated porcine cholecyst-derived bioscaffold for cardiac tissue engineering. Colloids Surf B Biointerfaces. 2017;157(157):130-137.

56. Jing X, Mi H-Y, Napiwocki BN, Peng X-F, Turng L-S. Mussel-inspired electroactive chitosan/graphene oxide composite hydrogel with rapid self-healing and recovery behavior for tissue engineering. Carbon. 2017; 125:557-570.

57. Luo J, Qin L, Kural MH, et al. Vascular smooth muscle cells derived from inbred swine induced pluripotent stem cells for vascular tissue engineering. Biomaterials. 2017;147:116-132.

58. Yi H, Forsythe $\mathrm{S}, \mathrm{He} \mathrm{Y}$, et al. Tissue-specific extracellular matrix promotes myogenic differentiation of human muscle progenitor cells on gelatin and heparin conjugated alginate hydrogels. Acta Biomater. 2017;62(62):222-233.

59. Schmidt CE, Leach JB. Neural Tissue Engineering: Strategies for Repair and Regeneration. Annu Rev Biomed Eng. 2003;5(1):293-347.

60. Wu Y, Wang L, Guo B, Shao Y, Ma PX, Px M. Electroactive biodegradable polyurethane significantly enhanced Schwann cells myelin gene expression and neurotrophin secretion for peripheral nerve tissue engineering. Biomaterials. 2016;87:18-31.

61. Pan M, Wang X, Chen Y, et al. Tissue engineering with peripheral blood-derived mesenchymal stem cells promotes the regeneration of injured peripheral nerves. Exp Neurol. 2017;292:92-101.

62. Carvalho CR, López-Cebral R, Silva-Correia J, et al. Investigation of cell adhesion in chitosan membranes for peripheral nerve regeneration. Mater Sci Eng C. 2017;71(1):1122-1134.

63. Moradian H, Keshvari H, Fasehee H, Dinarvand R, Faghihi S. Combining NT3-overexpressing MSCs and PLGA microcarriers for brain tissue engineering: A potential tool for treatment of Parkinson's disease. Mater Sci Eng C. 2017;76:934-943.

64. Rao J, Cheng Y, Liu Y, et al. A multi-walled silk fibroin/silk sericin nerve conduit coated with poly(lactic-co-glycolic acid) sheath for peripheral nerve regeneration. Mater Sci Eng C Mater Biol Appl. 2017;73(73): 319-332.

65. Nagai T, Ikegami Y, Mizumachi H, Shirakigawa N, Ijima H. Development of an in situ evaluation system for neural cells using extracellular matrix-modeled gel culture. J Biosci Bioeng. 2017;124(4):430-438.

66. Xia B, Lv Y. Dual-delivery of VEGF and NGF by emulsion electrospun nanofibrous scaffold for peripheral nerve regeneration. Mater Sci Eng C Mater Biol Appl. 2018;82(82):253-264.
International Journal of Nanomedicine

\section{Publish your work in this journal}

The International Journal of Nanomedicine is an international, peerreviewed journal focusing on the application of nanotechnology in diagnostics, therapeutics, and drug delivery systems throughou the biomedical field. This journal is indexed on PubMed Central, MedLine, CAS, SciSearch ${ }^{\circledR}$, Current Contents ${ }^{\circledR} /$ Clinical Medicine,

\section{Dovepress}

Journal Citation Reports/Science Edition, EMBase, Scopus and the Elsevier Bibliographic databases. The manuscript management system is completely online and includes a very quick and fair peer-review system, which is all easy to use. Visit http://www.dovepress.com/ testimonials.php to read real quotes from published authors. 